\title{
Screening for psychological distress in follow-up care to identify head and neck cancer patients with untreated distress
}

\author{
Anne-Marie H. Krebber ${ }^{1}$ - Femke Jansen ${ }^{1}$ • Pim Cuijpers ${ }^{2}$. \\ C. René Leemans ${ }^{1} \cdot$ Irma M. Verdonck-de Leeuw $^{1,2}$
}

Received: 11 September 2015 / Accepted: 7 December 2015 /Published online: 23 December 2015

(C) The Author(s) 2015. This article is published with open access at Springerlink.com

\begin{abstract}
Purpose The purpose of the study is to investigate screening in follow-up care to identify head and neck cancer (HNC) patients with untreated psychological distress.

Methods From November 2009 until December 2012, we investigated the use of OncoQuest (a touch screen computer system to monitor psychological distress (Hospital Anxiety and Depression Scale (HADS)) and quality of life (HRQOL; EORTC QLQ-C30 and H\&N35 module) in routine follow-up care. Patients who screened positive for psychological distress (HADS-T $>14$, HADS-A $>7$, or HADS-D $>7$ ) were asked whether they received psychological or psychiatric treatment. Results During the study period of 37 months, OncoQuest was used by 720 individual HNC patients, of whom 714 had complete HADS data. Psychological distress was present in 206 patients $(29 \%)$. Of those patients who fulfilled in- and exclusion criteria $(n=137), 25$ received psychological treatment $(18 \%)$. Receipt of psychological treatment was significantly related to a higher score on the HADS total scale (19.6 vs. $16.9 ; p=0.019$ ), a lower (worse) score on the EORTC QLQ-C30 scale emotional functioning (46.0 vs. 58.6; $p=0.023$ ), a higher (worse) score on fatigue (58.2 vs. 46.4; $p=0.032$ ), problems with sexuality (44.1 vs. $34.4 ; p=0.043$ ), oral pain (43.8 vs. $28.8 ; p=0.011)$ and speech problems $(37.0$ vs. $25.3 ; p=0.042)$.
\end{abstract}

Irma M. Verdonck-de Leeuw

im.verdonck@vumc.nl

1 Department of Otolaryngology/Head and Neck Surgery, VU University Medical Center, PO Box 7057, 1007, MB Amsterdam, The Netherlands

2 Department of Clinical Psychology, VU University, Van der Boechorststraat 1, 1081, BT Amsterdam, The Netherlands
Conclusions Screening for psychological distress via OncoQuest is beneficial because $82 \%$ of HNC patients identified with an increased level of distress who do not yet receive mental treatment were identified. Patients who did receive treatment reported more distress and worse quality of life, which may be explained because patients with more severe problems maybe more inclined to seek help or might be detected easier by caregivers and referred to supportive care more often.

Keywords Head and neck cancer · Oncology ·

Screening for psychological distress $\cdot$ Anxiety $\cdot$ Depression

\section{Introduction}

Psychosocial care is increasingly recognised as an integral part of quality cancer treatment [1]. In the Netherlands, government policy statements, various cancer specific guidelines, reflect broad scientific and societal support for a structured, integrated approach to psychosocial care for cancer patients $[2,3]$. Although there is evidence that psychosocial care is effective [4-6], referral rates are low [7, 8], and many patients have unmet needs, related to e.g. fatigue, sexuality issues and life stress [9-11]. The identification and support of cancer patients with psychological distress is a challenge [10, 12], especially in head and neck cancer (HNC) patients as they do not usually express their emotions spontaneously in front of the oncologists. One of the main barriers to deliver psychosocial cancer care in cancer patients is lack of screening for psychological distress in clinical practice to identify patients [13-16].

Fitch [15] stated that the need for identifying psychological distress is clear and there are suitable patient reported outcome measures (PROMs) available to perform this screening. The 
Distress Thermometer with the accompanying problem list is often used for assessment of each patient's unique needs [3, 17]. Other tools have emerged as well, such as Viewpoint [18], SupportScreen [19], ESRA-C [20], and CHES [21]. At the Department of Otolaryngology-Head and Neck Surgery of VU University Medical Center, efficient screening for distress followed by triage to care has become available in 2006 by a touch screen computer system (OncoQuest) that was implemented in routine clinical practice [7, 22, 23]. Via OncoQuest, patients complete quality of life (HRQOL) questionnaires (EORTC QLQ-C30 and condition-specific modules such as the EORTC QLQ-H\&N35) and the Hospital Anxiety and Depression Scale (HADS) [23]. OncoQuest is linked to the hospital patient information system. Data are processed in realtime and a care coordinator (a nurse specialised in HNC) can view the results by clear graphics on a computer in the consulting room and discuss these with the patient. In this prospective surveillance model, HRQOL can be repeatedly monitored and changes can be assessed; physical impairment, functional limitations and psychosocial distress can be identified in an early stage, information and psychoeducation can be provided, and, if necessary, supportive care including rehabilitation, psychosocial care and healthy lifestyle programs can be introduced.

Several studies have shown that using PROMs facilitates communication about patients' symptoms, functioning and distress between doctors, nurses and patients [16]. However, an international debate has emerged concerning screening for psychological distress in clinical practice with authors with solid arguments in favour of screening [12, 16, 24-27] and other authors with valid arguments against it [28-30]. For instance, Palmer et al. [29] reported that $36 \%$ of recently diagnosed breast cancer patients with elevated distress or a psychiatric disorder already received psychotropic medication. The authors argued that because of this relatively high percentage, screening all breast cancer patients is therefore not very effective. However, information on patients with other types of cancer is scarce, which hampers the discussion on pros and cons of screening for distress in clinical practice.

The aim of this study is to investigate screening in followup care to identify $\mathrm{HNC}$ patients with untreated psychological distress. Furthermore, sociodemographic and clinical factors and HRQOL outcomes will be investigated that may be associated with untreated psychological distress.

\section{Materials and methods}

\section{Study population}

All patients who routinely visited our outpatient clinic for follow-up care within a time frame of 37 months (November 2009-December 2012) were screened for psychological distress as part of standard clinical care. Patients who screened positive for psychological distress (HADS-T $>14$, HADS-A $>7$, or HADS-D $>7$ ) were assessed for eligibility for this crosssectional study and, when eligible, asked to participate in one interview on whether they received psychiatric or psychological treatment, and if so, which type of treatment. Eligible patients were those who were treated for cancer at least 1 month to 15 years earlier in VU University Medical Center for carcinoma of the lip, oral cavity, oropharynx, hypopharynx, nasopharynx, larynx or salivary glands (all stages), and who were treated with curative intent (all treatment modalities). Exclusion criteria were other (neurological) diseases causing cognitive dysfunction, end of treatment for a psychiatric disorder less than 2 months ago or being under treatment for another psychiatric disorder, not being reachable, insufficient knowledge of the Dutch language to fill out the questionnaires, and incomplete HADS data. Sociodemographic (age, gender) and clinical variables (tumour site and stage, treatment modality) were assessed by medical records audit.

The Medical Ethics Committee of the VU University Medical Center in Amsterdam approved this study. All procedures followed were in accordance with the Helsinki Declaration of 1975 , as revised in 2008, and in accordance with local laws and regulations.

\section{Screening for distress}

Since 2008, we offer all new HNC patients to use a touch screen computer system (OncoQuest) to complete the HADS and the EORTC QLQ-C30 and H\&N35 HRQOL questionnaires and to consult a specialised nurse, during follow-up visits after cancer treatment. If needed, a volunteer supports $\mathrm{HNC}$ patients using the computer system. Based on the results of OncoQuest (available in real-time in clear graphics on a computer screen), the nurse can identify and support HNC patients with psychological distress or problems regarding (HNC specific) HRQOL. On average, it takes 9 min to complete OncoQuest and the consultations with the nurse are estimated to take $10 \mathrm{~min}[7,22,23]$.

The HADS is a 14-item self-assessment scale for measuring distress (total HADS score (HADS-T)) with two subscales, anxiety (HADS-A) and depression (HADS-D). The HADS was specifically designed for use in the medically ill [31]. The total HADS score ranges from 0 to 42 , the subscales from 0 to 21 . A score of $>7$ on the anxiety scale, a score of $>7$ on the depression scale and/or a total HADS score of $>14$ is used as an indicator of a high level of psychological distress [31, 32].

The 30-item EORTC QLQ-C30 (version 3.0) includes a global HRQOL scale ( 2 items) and comprises five functional scales: physical functioning (5 items), role functioning (2 items), emotional functioning (4 items), cognitive functioning ( 2 items) and social functioning (2 items). There are three symptom scales (nausea and vomiting (2 items), fatigue (3 
items) and pain ( 2 items) and six single items relating to dyspnoea, insomnia, loss of appetite, constipation, diarrhoea and financial difficulties. The scores of the QLQ-C30 are linearly transformed to a scale of $0-100$, with a higher score indicating a higher (i.e., more positive) level of functioning or global HRQOL, or a higher (i.e., more negative) level of symptoms or problems [33, 34].

The EORTC QLQ-H\&N35 module covers specific HNC issues and comprises seven subscales: pain (4 items), swallowing (5 items), senses ( 2 items), speech (3 items), social eating (4 items), social contact ( 5 items) and sexuality (2 items). There are 11 single items covering problems with teeth, dry mouth, sticky saliva, cough, feeling ill, opening the mouth wide, weight loss, weight gain, use of nutritional supplements, feeding tubes, and painkillers. The scores of the QLQ-H\&N35 are linearly transformed to a scale of 0-100, with a higher score indicating a higher (i.e., more negative) level of symptoms or problems [35]. In the present study, the scales and the first six single items were used.

\section{The value of screening}

In the present study, eligible HNC patients in follow-up care with an increased level of psychological distress (HADS-T $>14$, HADS-A $>7$, or HADS-D >7) were asked whether they received psychiatric or psychological treatment. Based on earlier research [7, 36], it was expected that in clinical practice, 25-30\% of HNC patients would present with psychological distress of whom the majority do not receive psychological treatment. Screening for distress in follow-up care was defined to have added value if at least $50 \%$ of HNC patients diagnosed with psychological distress did not yet receive psychological or psychiatric treatment.

To provide information on sociodemographic, clinical factors and HRQOL variables possibly associated with untreated psychological distress, several univariate analyses were performed. Chi-square tests were used to investigate whether gender (male vs. female), tumour location (lip/oral cavity, oropharynx, hypopharynx/larynx, other), tumour stage based on the UICC TNM classification of malignant tumours (I, II, II, IV), treatment modality (single treatment (surgery or radiotherapy) vs. combination (surgery and (chemo)radiation)) or time since treatment (1-12 months vs. >12 months) were associated with untreated psychological distress. Independent $t$ tests or, in case of skewness, Mann-Whitney tests were used to investigate whether age, HADS-T, HADS-A, or HADS-D or the EORTC QLQ-C30 and H\&N35 subscales were associated with untreated psychological distress. All analyses were performed using the IBM Statistical Package for the Social Science (SPSS) version 20 (IBM Corp., Armonk, NY, USA). For all statistical analyses, a $p$ value $<0.05$ was considered statistically significant.

Fig. 1 Selection of patients

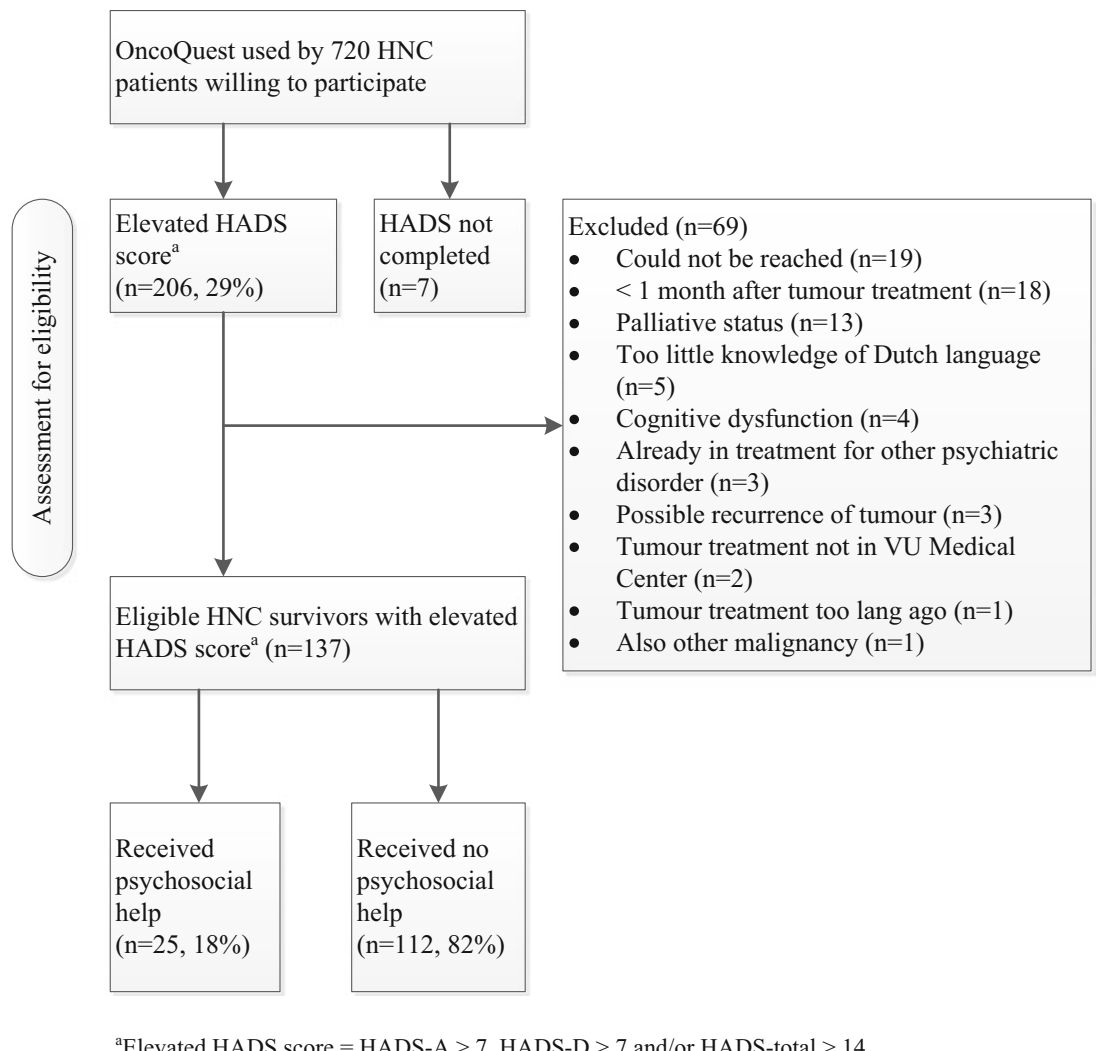




\section{Results}

\section{Prevalence of distress and receipt of treatment}

During the study period of 37 months, OncoQuest was used by $720 \mathrm{HNC}$ patients in follow-up care, of whom 714 had complete HADS data. Figure 1 shows the flow diagram of the selection of patients. Among the $714 \mathrm{HNC}$ patients, 206 patients screened positive for psychological distress $(29 \%)$. Of these 206 patients, 69 patients were excluded: 19 could not be reached, 18 were treated less than 1 month earlier, 13 were in the palliative phase of the disease, 5 had insufficient knowledge of the Dutch language, 4 had a cognitive dysfunction, 3 were currently under treatment for a psychiatric disorder other than anxiety or depression, 3 had possible tumour recurrence, 2 had not received treatment at VU University Medical Center, 1 had received tumour treatment too long ago, and 1 also had another untreated malignancy.

Among the $137 \mathrm{HNC}$ patients who screened positive for psychological distress during the study period and fulfilled the in- and exclusion criteria, 25 (18\%) received psychiatric or psychological treatment: 10 received counselling and psychomedication, 7 received psychomedication, 4 received counselling, and 1 received self-help and psychomedication, 3 patients did not provide information about their treatment.

\section{Factors related to receipt of psychological or psychiatric treatment}

Sociodemographic and clinical characteristics of the study population $(n=137)$ are provided in Table 1 , and regarding patient reported outcome measures (HADS, EORTC QLQC30 and H\&N35) in Table 2.

Receipt of psychological or psychiatric treatment (vs. no receipt) was not significantly related to gender, age, tumour location, tumour stage, tumour treatment and time since treatment (Table 1). Receipt of psychological or psychiatric treatment (vs. no receipt) was significantly related to a higher score on the HADS total scale (19.6 vs. $16.9 ; p=0.019$ ), a lower (worse) score on the EORTC QLQ-C30 scale emotional
Table 1 Overview of sociodemographic and clinical characteristics of the study sample

\begin{tabular}{|c|c|c|c|c|}
\hline & $\begin{array}{l}\text { Total sample } \\
(n=137) \\
N\end{array}$ & $\begin{array}{l}\text { Received no psychosocial } \\
\text { care }(n=112) \\
N(\%)\end{array}$ & $\begin{array}{l}\text { Received psychosocial } \\
\text { care }(n=25) \\
N(\%)\end{array}$ & $\begin{array}{l}p \\
\text { value }\end{array}$ \\
\hline Gender & & & & 0.92 \\
\hline Male & 92 & $75(81.5)$ & $17(18.5)$ & \\
\hline Female & 45 & $37(82.2)$ & $8(17.8)$ & \\
\hline Mean age (SD) & $61.7(10.1)$ & $61.9(9.8)$ & $61.0(11.1)$ & 0.74 \\
\hline Tumour location & & & & 0.55 \\
\hline Lip/oral cavity & 34 & $29(85.3)$ & $5(14.7)$ & \\
\hline Oropharynx & 36 & $28(77.8)$ & $8(22.2)$ & \\
\hline Hypopharynx/larynx & 46 & $36(78.3)$ & $10(21.7)$ & \\
\hline Other (e.g. parotis) & 21 & $19(90.5)$ & $2(9.5)$ & \\
\hline Tumour stadium & & & & 0.31 \\
\hline I & 32 & $29(90.6)$ & $3(9.4)$ & \\
\hline II & 28 & $20(71.4)$ & $8(28.6)$ & \\
\hline III & 31 & $25(80.6)$ & $6(19.4)$ & \\
\hline IV & 41 & $33(80.5)$ & $8(19.5)$ & \\
\hline Unknown & 5 & $5(100.0)$ & $0(0.0)$ & \\
\hline Tumour treatment & & & & 0.99 \\
\hline Single & 82 & $67(81.7)$ & $15(18.3)$ & \\
\hline Surgery & 23 & $19(82.6)$ & $4(17.4)$ & \\
\hline Radiotherapy & 59 & 48 (81.4) & 11 (18.6) & \\
\hline Combination & 55 & $45(81.8)$ & $10(18.2)$ & \\
\hline Chemoradiation & 25 & $21(84.0)$ & $4(16.0)$ & \\
\hline $\begin{array}{l}\text { Surgery and } \\
\text { (chemo)radiation }\end{array}$ & 30 & $24(80.0)$ & $6(20.0)$ & \\
\hline Time since treatment & & & & 0.53 \\
\hline $1-12$ months & 57 & $48(84.2)$ & $9(15.8)$ & \\
\hline$>12$ months & 80 & $64(80.0)$ & $16(20.0)$ & \\
\hline
\end{tabular}

A $p$ value $<0.05$ was considered statistically significant 
functioning ( 46.0 vs. 58.6; $p=0.023$ ), a higher (worse) score on fatigue ( 58.2 vs. $46.4 ; p=0.032)$ and problems with sexuality (44.1 vs. 34.4; $p=0.043$ ), and on the EORTC QLQH\&N35 scales oral pain (43.8 vs. $28.8 ; p=0.011)$ and speech problems (37.0 vs. $25.3 ; p=0.042)$.

\section{Discussion}

The present study revealed that among HNC patients, screening for distress is valuable because of the patients who screened positive for psychological distress (29\%); the majority ( $82 \%)$ did not yet receive treatment. This percentage of patients with untreated distress is much higher compared to $64 \%$ among newly diagnosed breast cancer patients as reported by Palmer et al. [29]. Therefore, and because two thirds of patients who screen positive may develop a full-blown depression if left untreated [37], we disagree with Palmer et al. and conclude that screening for distress is beneficial among HNC patients. Our conclusion supports the findings of Kotronoulas et al. [38], who reported in their recent review that routine use of PROMs increases communication about patient outcomes during consultations and that PROMs are associated with improved symptom control, increased supportive care, and patient satisfaction.

Table 2 Overview of outcomes on HADS, EORTC QLQ-C30 and H\&N35, and test statistics of between group differences

\begin{tabular}{|c|c|c|c|c|c|c|c|c|c|c|c|c|c|}
\hline & & $\begin{array}{l}\text { Total sample } \\
(N)\end{array}$ & Mean & SD & $\begin{array}{l}\text { No PC } \\
(N)\end{array}$ & Mean & SD & $\begin{array}{l}\mathrm{PC} \\
(\mathrm{N})\end{array}$ & Mean & SD & $\mathrm{t}$ or $\mathrm{Z}$ & df & $p$ value \\
\hline \multirow[t]{3}{*}{ HADS } & Depression & 137 & 8.77 & 3.61 & 112 & 8.42 & 3.12 & 25 & 10.32 & 5.06 & -1.80 & 28.19 & 0.082 \\
\hline & Anxiety & 135 & 8.64 & 3.64 & 110 & 8.49 & 3.64 & 25 & 9.28 & 3.65 & -0.98 & 133.00 & 0.335 \\
\hline & Total score & 135 & 17.39 & 5.27 & 110 & 16.88 & 4.79 & 25 & 19.60 & 6.70 & -2.37 & 133.00 & 0.019 \\
\hline \multirow[t]{15}{*}{ QLQ-C30 } & Global quality of life & 136 & 58.52 & 20.37 & 111 & 58.93 & 19.77 & 25 & 56.67 & 23.20 & 0.50 & 134.00 & 0.617 \\
\hline & Physical functioning & 135 & 70.86 & 21.08 & 110 & 72.42 & 20.28 & 25 & 64.00 & 23.49 & 1.82 & 133.00 & 0.071 \\
\hline & Role functioning & 136 & 60.66 & 29.30 & 111 & 62.76 & 28.15 & 25 & 51.33 & 32.96 & 1.78 & 134.00 & 0.078 \\
\hline & Emotional functioning & 137 & 56.27 & 25.08 & 112 & 58.56 & 23.95 & 25 & 46.00 & 27.86 & 2.299 & 135.00 & 0.023 \\
\hline & Cognitive functioning & 137 & 71.41 & 22.59 & 112 & 72.62 & 21.90 & 25 & 66.00 & 25.22 & 1.328 & 135.00 & 0.186 \\
\hline & Social functioning & 135 & 65.31 & 25.11 & 111 & 66.52 & 24.77 & 24 & 59.72 & 26.43 & 1.204 & 133.00 & 0.231 \\
\hline & Fatigue & 137 & 48.58 & 24.88 & 112 & 46.43 & 24.56 & 25 & 58.22 & 24.49 & -2.172 & 135.00 & 0.03 \\
\hline & Nausea/vomiting & 137 & 12.53 & 20.19 & 112 & 11.90 & 20.56 & 25 & 15.33 & 18.58 & -1.32 & n.a. & 0.19 \\
\hline & Pain & 137 & 37.47 & 28.57 & 112 & 35.57 & 28.08 & 25 & 46.00 & 29.77 & -1.662 & 135.00 & 0.10 \\
\hline & Dyspnoea & 136 & 27.94 & 28.75 & 112 & 28.27 & 27.66 & 24 & 26.39 & 34.02 & 0.29 & 134.00 & 0.77 \\
\hline & Insomnia & 137 & 37.71 & 34.02 & 112 & 36.31 & 34.24 & 25 & 44.00 & 32.94 & -1.022 & 135.00 & 0.31 \\
\hline & Loss of appetite & 137 & 29.93 & 33.40 & 112 & 29.46 & 33.41 & 25 & 32.00 & 33.99 & -0.342 & 135.00 & 0.73 \\
\hline & Constipation & 137 & 18.49 & 26.48 & 112 & 19.94 & 27.75 & 25 & 12.00 & 18.95 & -1.11 & n.a. & 0.27 \\
\hline & Diarrhoea & 137 & 9.98 & 21.53 & 112 & 10.71 & 22.47 & 25 & 6.67 & 16.67 & -0.74 & n.a. & 0.46 \\
\hline & Financial difficulties & 137 & 20.92 & 28.87 & 112 & 21.73 & 28.55 & 25 & 17.33 & 30.61 & -0.99 & n.a. & 0.32 \\
\hline \multirow[t]{13}{*}{ QLQ-H\&N35 } & Oral pain & 136 & 31.43 & 26.45 & 112 & 28.79 & 25.16 & 24 & 43.75 & 29.31 & -2.565 & 134.00 & 0.01 \\
\hline & Swallowing problems & 136 & 31.62 & 28.29 & 112 & 29.99 & 28.26 & 24 & 39.24 & 27.75 & -1.46 & 134.00 & 0.15 \\
\hline & Senses problems & 136 & 28.06 & 27.79 & 112 & 28.72 & 27.51 & 24 & 25.00 & 29.49 & 0.594 & 134.00 & 0.55 \\
\hline & Speech problems & 136 & 27.37 & 25.69 & 112 & 25.30 & 24.61 & 24 & 37.04 & 28.88 & -2.055 & 134.00 & 0.04 \\
\hline & Trouble with social eating & 134 & 34.08 & 30.36 & 110 & 31.74 & 28.86 & 24 & 44.79 & 35.17 & -1.927 & 132.00 & 0.06 \\
\hline & Trouble with social contact & 135 & 17.93 & 19.77 & 111 & 16.04 & 17.32 & 24 & 26.67 & 27.31 & -1.48 & n.a. & 0.14 \\
\hline & Less sexuality & 132 & 40.15 & 36.89 & 109 & 36.54 & 34.36 & 23 & 57.25 & 44.05 & -2.122 & 27.918 & 0.04 \\
\hline & Teeth problems & 136 & 24.75 & 31.95 & 112 & 22.62 & 30.42 & 24 & 34.72 & 37.40 & -1.56 & n.a. & 0.12 \\
\hline & Trouble with opening mouth & 136 & 29.90 & 33.77 & 112 & 27.68 & 32.23 & 24 & 40.28 & 39.29 & -1.67 & 134 & 0.10 \\
\hline & Dry mouth & 136 & 51.72 & 36.47 & 112 & 53.27 & 36.20 & 24 & 44.44 & 37.64 & 1.077 & 134 & 0.28 \\
\hline & Sticky saliva & 136 & 42.40 & 34.54 & 112 & 43.15 & 34.26 & 24 & 38.89 & 36.34 & 0.548 & 134 & 0.59 \\
\hline & Coughing & 136 & 33.33 & 29.26 & 112 & 33.04 & 28.47 & 24 & 34.72 & 33.30 & -0.255 & 134 & 0.80 \\
\hline & Feeling ill & 136 & 30.64 & 30.91 & 112 & 28.87 & 30.18 & 24 & 38.89 & 33.57 & -1.447 & 134 & 0.5 \\
\hline
\end{tabular}

In some cases, the total group was smaller than 137 because of missing values

No $P C$ received no psychosocial care, $P C$ received psychosocial care, $S D$ standard deviation, n.a. not applicable

A $p$ value $<00.05$ was considered statistically significant 
Receipt of psychological or psychiatric treatment was significantly related to a higher score on the HADS total scale, a lower (worse) score on the EORTC QLQ-C30 scale emotional functioning, a higher (worse) score on fatigue and problems with sexuality, and on the EORTC QLQ-H\&N35 scales oral pain and speech problems. An explanation for these findings might be that patients with more severe problems are more inclined to seek help. But also, these patients might be detected easier by caregivers during follow-up consultation and therefore are referred to supportive care earlier. Carlson et al. reported that full screening (online use of PROMs with a personalised printout of results and a list of contact details of services to help with the identified problems) and triage to care (full screening plus the opportunity to speak with a care professional who could refer to services directly) both result in the most benefit for lung cancer patients, compared to screening alone. Fewer patients in the triage group reported a problem with coping (12.9\%) compared with patients in the minimal (23.9\%) and full (26.9\%) screening groups [26]. Mitchell concluded that screening for distress and monitoring HRQOL in clinical practice is likely to benefit communication and referral for psychosocial help, and that, it has the potential to influence patient well-being but only if barriers are addressed [16]. However, understanding about the complexities of implementing screening programs is still unfolding [15]. In earlier studies, it was argued that incorporating PROMs in clinical practice should aim at equipping health professionals to use patient PROMs data in managing patients, should employ more condition-specific (rather than generic) PROMs, should improve the interpretability of the PROM data feedback to both medical staff and patients, and should support patients to improve their self-efficacy to manage illnessrelated issues [39]. Recently, key barriers were identified as lack of training and support, low acceptability, and failure to link treatment to the screening results [16]. Also, further implementation research is needed to advance knowledge about the most effective strategies in the context of cancer care [27].

A limitation to our study is that we missed information about the receipt of psychosocial care for $10 \%$ of the participating HNC patients because they could not be reached. However, these patients had mainly borderline HADS scores and additional information about referral to psychological services was not present in their medical dossiers. Therefore, these patients are suspected to not have received any psychosocial treatment. Another limitation of the study is that we do not know whether patients, who did receive treatment, did so as a result of distress screening or whether they already received such treatment. Furthermore, we do not know how many patients, who did not receive psychological treatment or psychiatric treatment ( $82 \%$ ), had unmet psychological care needs. Based on earlier research [40, 41] and clinical practice, our estimation is that many patients with psychological distress do not want to be referred to psychological care. This was the main reason to start a trial on stepped care in which patients are offered low-intensity interventions like self-help first, before being referred to a psychologist or psychiatrist [42]. Although OncoQuest is valued by the coordinating nurse and by patients, not all eligible patients make use of OncoQuest, which may have resulted in selection bias. A mixed method study including qualitative and quantitative research measures is ongoing and will provide detailed insight into possible barriers and facilitators enabling optimization of OncoQuest. In their randomised clinical trial, Carlson et al. [43], examining the impact of screening for distress followed by personalised triage versus computerised triage, concluded that the best model of screening may be to incorporate personalised triage for patients indicating high levels of depression and anxiety while providing computerised triage for others. Further research is needed on best-practice approaches for implementing sustainable and acceptable screening for distress and triage programs in clinical settings.

\section{Conclusion}

Screening for psychological distress among HNC patients is beneficial to identify patients with psychological distress who do not yet receive treatment. Via OncoQuest, a broad spectrum of HRQOL is monitored (EORTC QLQ-C30 and QLQHN35 module), enabling identification of not only psychological distress but also of other problems.

Acknowledgments The study is funded by The Netherlands Organisation for Health Research and Development, grant-number 300020012.

Compliance with ethical standards The Medical Ethics Committee of the VU University Medical Center in Amsterdam approved this study. All procedures followed were in accordance with the Helsinki Declaration of 1975, as revised in 2008, and in accordance with local laws and regulations.

Conflict of interest The authors declare that they have no competing interests.

Open Access This article is distributed under the terms of the Creative Commons Attribution-NonCommercial 4.0 International License (http:// creativecommons.org/licenses/by-nc/4.0/), which permits any noncommercial use, distribution, and reproduction in any medium, provided you give appropriate credit to the original author(s) and the source, provide a link to the Creative Commons license, and indicate if changes were made.

\section{References}

1. Fitch MI (2008) Supportive care framework. Can Oncol Nurs J 18: 6-24

2. Comprehensive Cancer Centre the Netherlands (IKNL) (2011) Guideline Oncological rehabilitation. http://www.oncoline.nl/ oncologische-revalidatie Accessed June 29, 2015 
3. Comprehensive Cancer Centre the Netherlands (IKNL) (2010) Guideline Detection of need for psychosocial care. http://www. oncoline.n1/detecerenbehoeftepsychosocialezorg Accessed June 29,2015

4. Hart SL, Hoyt MA, Diefenbach M, Anderson DR, Kilbourn KM, Craft LL, Steel JL, Cuijpers P, Mohr DC, Berendsen M, Spring B, Stanton AL (2012) Meta-analysis of efficacy of interventions for elevated depressive symptoms in adults diagnosed with cancer. $\mathrm{J}$ Natl Cancer Inst 104:990-1004. doi:10.1093/jnci/djs256

5. Faller H, Schuler M, Richard M, Heckl U, Weis J, Kuffner R (2013) Effects of psycho-oncologic interventions on emotional distress and quality of life in adult patients with cancer: systematic review and meta-analysis. J Clin Oncol 31:782-793. doi:10.1200/JCO.2011. 40.8922

6. Galway K, Black A, Cantwell M, Cardwell CR, Mills M, Donnelly M (2012) Psychosocial interventions to improve quality of life and emotional wellbeing for recently diagnosed cancer patients. Cochrane Database Syst Rev 11:CD007064. doi:10.1002/ 14651858.CD007064.pub2

7. Verdonck-de Leeuw IM, de Bree R, Keizer AL, Houffelaar T, Cuijpers P, van der Linden MH, Leemans CR (2009) Computerized prospective screening for high levels of emotional distress in head and neck cancer patients and referral rate to psychosocial care. Oral Oncol 45:e129-133. doi:10.1016/j. oraloncology.2009.01.012

8. Waller A, Williams A, Groff SL, Bultz BD, Carlson LE (2013) Screening for distress, the sixth vital sign: examining self-referral in people with cancer over a one-year period. Psychooncology 22(2):388-395. doi:10.1002/pon.2102

9. Carlson LE, Angen M, Cullum J, Goodey E, Koopmans J, Lamont L, MacRae JH, Martin M, Pelletier G, Robinson J, Simpson JS, Speca M, Tillotson L, Bultz BD (2004) High levels of untreated distress and fatigue in cancer patients. Br J Cancer 90:2297-2304. doi:10.1038/sj.bjc.6601887

10. Harrison JD, Young JM, Price MA, Butow PN, Solomon MJ (2009) What are the unmet supportive care needs of people with cancer? A systematic review. Support Care Cancer 17:1117-1128. doi:10. 1007/s00520-009-0615-5

11. Maguire R, Papadopoulou C, Kotronoulas G, Simpson MF, McPhelim J, Irvine L (2013) A systematic review of supportive care needs of people living with lung cancer. Eur J Oncol Nurs 17:449-464. doi:10.1016/j.ejon.2012.10.013

12. Carlson LE, Waller A, Mitchell AJ (2012) Screening for distress and unmet needs in patients with cancer: review and recommendations. J Clin Oncol 30:1160-1177. doi:10.1200/jco.2011.39.5509

13. Donovan KA, Jacobsen PB (2013) Progress in the implementation of NCCN guidelines for distress management by member institutions. J Natl Compr Canc Netw 11:223-226

14. Mitchell AJ, Kaar S, Coggan C, Herdman J (2008) Acceptability of common screening methods used to detect distress and related mood disorders-preferences of cancer specialists and non-specialists. Psychooncology 17:226-236. doi:10.1002/pon.1228

15. Fitch MI (2011) Screening for distress: a role for oncology nursing. Curr Opin Oncol 23:331-337. doi:10.1097/CCO.0b013e32834791a1

16. Mitchell AJ (2013) Screening for cancer-related distress: when is implementation successful and when is it unsuccessful? Acta Oncol 52:216-224. doi:10.3109/0284186X.2012.745949

17. Mitchell AJ (2010) Short screening tools for cancer-related distress: a review and diagnostic validity meta-analysis. J Natl Compr Canc Netw 8:487-494

18. Snyder CF, Jensen R, Courtin SO, Wu AW (2009) PatientViewpoint: a website for patient-reported outcomes assessment. Qual Life Res 18:793-800. doi:10.1007/s11136-009-9497-8

19. Loscalzo M, Clark K, Dillehunt J, Rinehart R, Strowbridge R, Smith D (2010) SupportScreen: a model for improving patient outcomes. J Natl Compr Canc Netw 8:496-50
20. Berry DL, Blumenstein BA, Halpenny B, Wolpin S, Fann JR, Austin-Seymour M, Bush N, Karras BT, Lober WB, McCorkle R (2011) Enhancing patient-provider communication with the electronic self-report assessment for cancer: a randomized trial. J Clin Oncol 29:1029-1035. doi:10.1200/jco.2010.30.3909

21. Holzner B, Giesinger JM, Pinggera J, Zugal S, Schopf F, Oberguggenberger AS, Gamper EM, Zabernigg A, Weber B, Rumpold G (2012) The Computer-based Health Evaluation Software (CHES): a software for electronic patient-reported outcome monitoring. BMC Med Inform Decis Mak 12:126. doi:10. 1186/1472-6947-12-126

22. Cnossen IC, de Bree R, Rinkel RN, Eerenstein SE, Rietveld DH, Doornaert P, Buter J, Langendijk JA, Leemans CR, Verdonck-de Leeuw IM (2012) Computerized monitoring of patient-reported speech and swallowing problems in head and neck cancer patients in clinical practice. Support Care Cancer 20:2925-2931. doi:10. 1007/s00520-012-1422-y

23. de Bree R, Verdonck-de Leeuw IM, Keizer AL, Houffelaar A, Leemans CR (2008) Touch screen computer-assisted health-related quality of life and distress data collection in head and neck cancer patients. Clin Otolaryngol 33:138-142. doi:10.1111/j.1749-4486. 2008.01676.x

24. Carlson LE, Groff SL, Maciejewski O, Bultz BD (2010) Screening for distress in lung and breast cancer outpatients: a randomized controlled trial. J Clin Oncol 28:4884-4891. doi:10.1200/JCO. 2009.27.3698

25. Carlson LE, Waller A, Groff SL, Bultz BD (2013) Reply: comment on 'Online screening for distress, the 6th vital sign, in newly diagnosed oncology outpatients: randomised controlled trial of computerised vs personalised triage'- psychological distress in patients with cancer: is screening the effective solution? Br J Cancer 108:2631-2632. doi:10.1038/bjc.2013.287

26. Carlson LE, Waller A, Groff SL, Bultz BD (2013) Screening for distress, the sixth vital sign, in lung cancer patients: effects on pain, fatigue, and common problems - secondary outcomes of a randomized controlled trial. Psychooncology 22:1880-1888. doi:10.1002/ pon. 3223

27. Howell D, Hack TF, Green E, Fitch M (2014) Cancer distress screening data: translating knowledge into clinical action for a quality response. Palliat Support Care 12:39-51. doi:10.1017/ S1478951513000382

28. Coyne JC (2013) Benefits of screening cancer patients for distress still not demonstrated. Br J Cancer 108:736-737. doi:10.1038/bjc. 2013.16

29. Palmer SC, Taggi A, Demichele A, Coyne JC (2012) Is screening effective in detecting untreated psychiatric disorders among newly diagnosed breast cancer patients? Cancer 118:2735-2743. doi:10. 1002/cncr.26603

30. Palmer SC, van Scheppingen C, Coyne JC (2011) Clinical trial did not demonstrate benefits of screening patients with cancer for distress. J Clin Oncol 29:e277-278. doi:10.1200/JCO.2010.34.1206, author reply e279-280

31. Zigmond AS, Snaith RP (1983) The hospital anxiety and depression scale. Acta Psychiatr Scand 67:361-370

32. Spinhoven P, Ormel J, Sloekers PP, Kempen GI, Speckens AE, Van Hemert AM (1997) A validation study of the Hospital Anxiety and Depression Scale (HADS) in different groups of Dutch subjects. Psychol Med 27:363-370

33. Aaronson NK, Ahmedzai S, Bergman B, Bullinger M, Cull A, Duez NJ, Filiberti A, Flechtner H, Fleishman SB, de Haes JC et al (1993) The European Organization for Research and Treatment of Cancer QLQ-C30: a quality-of-life instrument for use in international clinical trials in oncology. $\mathrm{J}$ Natl Cancer Inst 85:365-376

34. Bjordal K, Ahlner-Elmqvist M, Tollesson E, Jensen AB, Razavi D, Maher EJ, Kaasa S (1994) Development of a European 
Organization for Research and Treatment of Cancer (EORTC) questionnaire module to be used in quality of life assessments in head and neck cancer patients. EORTC Quality of Life Study Group. Acta Oncol 33:879-885

35. Fayers P, Bottomley A, Group EQoL, Unit QoL (2002) Quality of life research within the EORTC-the EORTC QLQ-C30. European Organisation for Research and Treatment of Cancer. Eur J Cancer 38(Suppl 4):S125-133

36. Verdonck-de Leeuw IM, Eerenstein SE, Van der Linden MH, Kuik DJ, de Bree R, Leemans CR (2007) Distress in spouses and patients after treatment for head and neck cancer. Laryngoscope 117:238 241. doi:10.1097/01.mlg.0000250169.10241.58

37. Weissman MM, Neria Y, Gameroff MJ, Pilowsky DJ, Wickramaratne P, Lantigua R, Shea S, Olfson M (2010) Positive screens for psychiatric disorders in primary care: a long-term follow-up of patients who were not in treatment. Psychiatr Serv 61: 151-159. doi:10.1176/appi.ps.61.2.151

38. Kotronoulas G, Kearney N, Maguire R, Harrow A, Di Domenico D, Croy S, MacGillivray S (2014) What is the value of the routine use of patient-reported outcome measures toward improvement of patient outcomes, processes of care, and health service outcomes in cancer care? A systematic review of controlled trials. J Clin Oncol 32:1480-1501. doi:10.1200/jco.2013.53.5948

39. Luckett T, Butow PN, King MT (2009) Improving patient outcomes through the routine use of patient-reported data in cancer clinics: future directions. Psychooncology 18:1129-1138. doi:10. 1002/pon. 1545

40. Jansen F, van Uden-Kraan CF, van Zwieten V, Witte BI, Verdonck-de Leeuw IM (2015) Cancer survivors' perceived need for supportive care and their attitude towards selfmanagement and eHealth. Support Care Cancer 23:1679-88. doi:10.1007/s00520-014-2514-7

41. Lubberding S, van Uden-Kraan CF, Te Velde EA, Cuijpers P, Leemans CR, Verdonck-de Leeuw IM (2015) Improving access to supportive cancer care through an eHealth application: a qualitative needs assessment among cancer survivors. J Clin Nurs 24: 1367-79. doi:10.1111/jocn.12753

42. Krebber AM, Leemans CR, de Bree R, van Straten A, Smit F, Smit EF, Becker A, Eeckhout GM, Beekman AT, Cuijpers P, Verdonck-de Leeuw IM (2012) Stepped care targeting psychological distress in head and neck and lung cancer patients: a randomized clinical trial. BMC cancer 12:173. doi:10.1186/ 1471-2407-12-173

43. Carlson LE, Waller A, Groff SL, Zhong L, Bultz BD (2012) Online screening for distress, the 6th vital sign, in newly diagnosed oncology outpatients: randomised controlled trial of computerised vs personalised triage. Br J Cancer 107:617-625. doi:10.1038/bjc. 2012.309 